\title{
El sector financiero y el lavado de dinero
}

\author{
Alberto Montes Farro \\ Docente Asociado de la Facultad de Ciencias Contables
}

\section{RESUMEN}

El lavado de dinero es el método por el cual una persona criminal, o una organización criminal, procesa las ganancias financieras resultando de actividades ilegales. Como en cualquier negocio legitimo, una empresa criminal necesita tener rápido acceso a las ganancias adquiridas a través de la venta de bienes y servicios. A diferencia de un negocio legitimo, sin embargo, la empresa criminal no puede operar abiertamente. Debe esconder la naturaleza, localidad, procedencia, propiedad o control de beneficios "producidos por su negocio", para evitar ser detectado por las autoridades competentes. A través del lavado de dinero, el criminal (sea una persona, una organización, o un especialistas en lavado de dinero) transforma las ganancias monetarias derivadas de una actividad criminal en fondos provenientes, aparentemente, de una fuente legal.

Toda actividad del lavado de dinero cae en una de dos categorias: conversión o movimiento. La conversión tiene lugar cuando los productos financieros cambian de una forma a otra, como cuando se compra un giro o un automóvil con ganancias ilícitas; los productos ilícitos originales han cambiado de forma, de dinero en efectivo a un giro o a un automóvil.

Se produce un movimiento, cuando los mismos productos financieros cambian de localidades, como cuando los fondos son transferidos telegráficamente a otra ciudad o enviados a través del correo. Un comerciante legitimo hace cada día los mismos tipos de conversiones o movimientos para su empresa (por ejemplo: adquisiciones de capital, inversiones, ventas de productos, distribución de dividendos, pago de salarios). En el proceso de lavado de dinero le permite disfrazar la verdadera procedencia ilegal de los fondos.

Por lo anterior, el presente artículo pretende involucrar el sector financiero ya que se debe adoptar medidas especiales para prevenir el lavado de activos, que contribuyan a la acción de las autoridades en la prevención y castigo de este delito. Estas medidas tienen un carácter especial y superan el simple deber de colaboración con la autoridad que corresponde a todo ciudadano.

Es por ello que estudios continuos sobre el tema, tienen la mayor importancia, en la medida en que brindan al sector financiero un mayor conocimiento y entendimiento de las disposiciones existentes para enfrentar el lavado de activos.

Palabras clave: Lavado de activos, instrumentos de lavado de dinero, actividad ilícita, técnicas y mecanismo de lavado de dinero. 


\section{INTRODUCCIÓN}

El tema relacionado con los mecanismos de detección y prevención del lavado de activos, de cuya legislación a nivel latinoamericano está en desarrollo, ha adquirido en los últimos tiempos una especial relevancia mundial, en la medida en que se ha tomado conciencia de que una de las más eficientes formas en que los Estados pueden debilitar la estructura económica de las empresas criminales, es mediante la prevención y represión del lavado de los activos producto de tales actividades.

El lavado de activos es un fenómeno de dimensiones internacionales. Dada la interdependencia existente entre los países y el alto desarrollo tecnológico de las telecomunicaciones, los capitales fluyen fácilmente por el sistema financiero mundial. Esto permite a la delincuencia organizada operar local e internacionalmente, por lo cual el lavado de activos normalmente involucra movimientos de capitales entre distintos países.

De allí la necesidad de la cooperación internacional, cooperación que ha sido reconocida por numerosos gobiernos y ha redundado en diversos acuerdos en el ámbito internacional. En buena medida, estos acuerdos han contribuido a fortalecer los ordenamientos nacionales y mejorar los mecanismos de cooperación e intercambio de información y pruebas en diversos países.

En efecto, organismos como la Organización de las Naciones Unidas (ONU) y la Organización de los Estados Americanos (OEA) han promovido la adopción de normas específicas en esta materia.

El Grupo de Acción Financiera (GAFI) y la Comisión Interamericana para el Control del Abuso de Drogas, de la Organización de los Estados Americanos (CICAD-OEA) se han constituido en un apoyo fundamental en los esfuerzos de los Estados para el desarrollo de una política integral contra las diversas manifestaciones de las actividades delictuales y, especialmente, contra el lavado de activos.

Puede afirmarse que en el ámbito nivel latinoamericano, los mecanismos de control y prevención del lavado de activos adoptados al interior de cada uno del continente, responden a parámetros de aplicación internacional.

La mayoría de los Estados miembros de la OEA han adoptado o se han comprometido a adoptar en su ordenamiento jurídico interno, las recomendaciones contenidas en el Reglamento Modelo de la CICAD-OEA. Esta adopción de recomendaciones internacionales se refleja de manera integral en las distintas áreas de la legislación interna, que de algún modo se relacionan con el lavado de activos.

Las disposiciones que regulan el sistema financiero, el sistema penal y la estructura del aparato jurisdiccional en los países latinoamericanos, en cuanto hace al tema del lavado de activos, se encuentran adecuadas a los estándares internacionales en la materia.

La acción de las autoridades contra el lavado de activos, tiene la mayor importancia en el entorno actual, en el cual se han modificado de manera sustancial las políticas contra la delincuencia. En este tiempo, se ha visto que una de las herramientas más efectivas contra el delito, es perseguir la riqueza producto de las acciones cometidas por fuera de la ley, siendo, la acción contra el lavado de activos, una de las herramientas más efectivas.

Se requiere un trabajo conjunto para controlar el flujo de capitales entre los distintos estados, práctica habitual de las organizaciones criminales para eludir la acción de las autoridades. 


\section{ETAPAS DEL LAVADO DE DINERO}

En la etapa inicial o de colocación, el lavador de dinero dispone de los productos en efectivo originalmente derivados del crimen, ya sea insertándolos directamente dentro del sistema financiero o moviéndolos a otro lugar. En la etapa de estratificación, el lavador de dinero intenta separar los productos ilegales de su procedencia ilícita sometiéndolos a una serie de transacciones financieras (tanto de conversiones como de movimientos). El lavador espera con eso no solo hacer la conexión más difícil, sino imposible de detectar. La última etapa o de integración es donde el lavador crea la justificación o explicación que parece legítima para los fondos ahora lavados y los mete abiertamente dentro de la economía legítima como inversiones o a través de adquisiciones de bienes.

El lavador de dinero usa una variedad de técnicas para lavar los productos ilícitos. Además, él tiene a su disposición ciertos mecanismos e instrumentos monetarios comunes que facilitan su trabajo. En términos simples, el lavador de dinero es solo un comerciante cuya meta es maximizar ganancias para proveer un servicio financiero mientras minimiza el riesgo para él y sus clientes. Sin embargo, como el lavador provee un servicio ilegal, debe usar versiones modificadas de técnicas comerciales legítimas.

\section{TÉCNICAS DEL LAVADO DE DINERO}

Una técnica de lavado de dinero es un procedimiento individual o paso en el lavado de productos ilegales, similar a una transacción comercial individual legítima. Algunas de las técnicas más comunes de dinero incluyen las siguientes:
- Estructurar o hacer "Trabajo de Pitufo" o "Trabajo de hormiga".

- Complicidad de un funcionario u organización: mezclar.

- Compañías de fachada: mal uso de las listas de excepciones del CTR.

- Compras de bienes o instrumentos monetarios con productos en efectivo.

- Contrabando de efectivo: transferencias telegráficas o electrónicas.

- Cambiar la forma de forma de productos ilícitos por medio de compras de bienes o instrumentos monetarios: establecimiento de compañías de portafolio o nominales ("shell company"): venta o exportación de bienes.

Otras técnicas usadas para el lavado del dinero son:

- Ventas fraudulentas de bienes inmuebles.

- Transferencias inalámbricas o entre corresponsales.

- Falsas facturas de importación/exportación o "doble facturación".

- Garantías de préstamos.

- Venta de valores a través de falsos intermediarios.

\section{MECANISMOS DEL LAVADO DE DINERO}

Un mecanismo del lavado de dinero es una empresa comercial o financiera que facilita el lavado. Muchas de las mismas empresas financieras (por ejemplo, bancos y casas de cambio) que participan en negocios legítimos también toman parte, a sabiendas o sin saber, en el lavado de fondos ilegales. Según prácticas comerciales modernas, las distinciones entre los varios tipos de negocios que ofrecen servicios financieros se han vuelto 
borrosas. De este modo, un negocio de cambio de moneda puede también servir para trasmitir fondos, o un prestamistas puede cambiar cheques y operar como agente de una compañía telegráfica, por ejemplo. Algunos de los tipos de mecanismos más comunes en el lavado de dinero son:

- Bancos, incluyendo bancos comerciales, bancos privados, e instituciones de ahorro (por ejemplo, asociaciones de ahorro y préstamos, bancos cooperativos, etc.).

- Corredores de bolsa o de productos.

- Bancos o compañías de inversiones (por ejemplo, fondos mutuos).

- Cambios de moneda extranjera

- Libradores, tenedores o beneficiarios o cajeros de cheques de viajero, cheques de giro, o instrumentos similares.

- El servicio postal (giros postales).

- Prestamistas.

- Compañías de préstamos o financieras.

- Compañías que operan en el envió de remesas o envíos de dinero.

- Casinos o casas de juego.

- Compañías de seguros.

- Operadores de metales preciosos, piedras o joyas.

- Agencias de viaje.

- Venta de automotores minorista (incluye automóviles, aviones y embarcaciones).

- Compañías inmobiliarias.

\subsection{Instrumentos para el lavado de dinero}

Según lo mencionado anteriormente, un lavador de dinero usa mucho los instrumentos financieros que también son usados por las empresas comerciales legítimas. Ciertos instrumentos financieros son más conducentes o preferidos por los lavadores de dinero por su conveniencia o porque ellos facilitan el ocultamiento de la procedencia original de los fondos que ellos representan. Los siguientes elementos son algunos de los instrumentos para el lavado de dinero más frecuentemente usados:

- Dinero en circulación.

- Cheques en gerencia.

- Cheques personales.

- Giros.

- Giros bancarios.

\section{SECTORES ECONÓMICOS Y EL LAVADO DE ACTIVOS}

El combate del lavado de activos involucra a todos los sectores económicos. En el caso del sector financiero, su responsabilidad es mayor. El sector financiero recibe y canaliza buena parte del flujo de capitales de la economía, lo cual facilita que el dinero de procedencia ilícita se confunda con recursos de origen legal. Por lo anterior, el sector financiero es especialmente vulnerable a ser utilizado sin su consentimiento ni conocimiento para el lavado de activos.

La difusión de las normas pertinentes en los países latinoamericanos resulta fundamental para lograr una mayor eficacia de las mismas en el combate contra la empresa criminal, más allá de la represión del delito en sí mismo considerado y de la simple represión penal al delincuente. 
SEÑALES DE ALERTA

\begin{tabular}{|c|c|}
\hline TIPO DE OPERACIONES & TRANSACCIONES INUSUALES O SOSPECHOSAS \\
\hline En efectivo & $\begin{array}{l}\text { Depósitos importantes y no usuales de dinero en efectivo, en cuentas cuyos depósitos usualmente } \\
\text { se realizan mediante cheques u otros documentos. } \\
\text { Apertura de Depósitos a Plazo de clientes ocasionales, por montos importantes, que podrían llegar } \\
\text { a convertirse en garantía de créditos en una segunda instancia. } \\
\text { Incremento de depósitos en efectivo por importes pequeños, pero cuya suma totaliza montos } \\
\text { significativos. } \\
\text { Clientes que buscan cambiar grandes cantidades de billetes de pequeña denominación por otras } \\
\text { más grandes. } \\
\text { Entregaso depósitos de dinero en efectivo para cubrir demandas de cheques bancarios, transferencias } \\
\text { de dinero u otros instrumentos financieros negociables e inmediatamente realizables. } \\
\text { Transferencias de grandes cantidades de dinero, desde o hacia el exterior, con instrucciones del } \\
\text { cliente, de pagarse en efectivo. } \\
\text { Frecuentes cambios de dólares en efectivo en otras monedas o viceversa. } \\
\text { Depósitos de clientes que con cierta frecuencia, contienen billetes o documentos falsificados. } \\
\text { Abonos en efectivo de importes no atractivos, en varias cuentas de un mismo cliente y cuya suma } \\
\text { se considera importante. }\end{array}$ \\
\hline De préstamos & $\begin{array}{l}\text { Clientes que cancelan, inesperadamente, préstamos problemáticos sin que se tenga conocimiento } \\
\text { del origen de los recursos. } \\
\text { Petición de préstamo garantizado por activos depositados en la entidad financiera o por terceros, } \\
\text { cuyo origen es desconocido o su valor no guarda relación con la situación del cliente. }\end{array}$ \\
\hline & $\begin{array}{l}\text { Clientes que reciben o efectúan, de o hacia países asociados con la producción, elaboración, venta } \\
\text { de drogas o con organizaciones terroristas, pagos regulares y en grandes cantidades, y que se } \\
\text { sospecha que no sean operaciones de buena fe. } \\
\text { Clientes extranjeros con base en países donde existe producción o tráfico de drogas. } \\
\text { Uso de cartas de créditos y otros métodos de financiación comercial para mover dinero entre países, } \\
\text { y que no tenga relación con la actividad del cliente. } \\
\text { Cartas de Crédito, al portador, aún cuando éstas sean emitidas por un banco de primera clase y } \\
\text { que además tengan el ofrecimiento de sustancial descuento. Lo mismo es válido en el caso de } \\
\text { Depósitos a Plazo en moneda extranjera, los cuales también pueden ser utilizados como garantía. } \\
\text { Créditos garantizados, con Carta de Crédito, en los cuales desde un principio el cliente ofrece } \\
\text { pagarlos al vencimiento, ejecutando la garantía. } \\
\text { Cuentas corrientes o clientes que reciben muchas Órdenes de Pago por montos pequeños o Money } \\
\text { Orders o Cashier's Checks. } \\
\text { Créditos garantizados por documentos de bancos externos, establecidos en "paraísos } \\
\text { financieros". } \\
\text { Carta de crédito que se transfiere parcialmente a un tercero para que éste provea la mercadería, } \\
\text { quedando el beneficiario original con un diferencial a favor. }\end{array}$ \\
\hline & $\begin{array}{l}\text { En el caso de Tarjetas de crédito, funciona cuando el titular hace anticipos de pago a la tarjeta, en } \\
\text { pequeñas cantidades y en forma repetitiva, para dejarla con saldo acreedor. Luego de un tiempo, } \\
\text { solicitan la cancelación de la tarjeta y la devolución del saldo. } \\
\text { Clientes que no actúan por cuenta propia y no quieren revelar la verdadera identidad del } \\
\text { beneficiario. } \\
\text { Clientes que, evidencian movimientos de depósitos y débitos sin consistencia respecto a sus } \\
\text { actividades. } \\
\text { Clientes con uso intensivo y creciente de Caja de Seguridad, tanto en el número de personas } \\
\text { usuarias como en frecuencia de visitas y en especial clientes recién captados o poco conocidos. } \\
\text { Clientes que mantienen simultáneamente cuentas con varias instituciones financieras, dentro de la } \\
\text { misma localidad. En especial si el Banco conoce que el cliente, antes de hacer una transferencia de } \\
\text { fondos de todas ellas, realiza una consolidación de saldos. } \\
\text { Cliente que usa diferentes cajeros para efectuar operaciones con efectivo. } \\
\text { Representantes de empresas que evitan el contacto con la oficina. } \\
\text { Compra y venta de un instrumento financiero sin ningún propósito aparente o en circunstancias que } \\
\text { son poco usuales. }\end{array}$ \\
\hline
\end{tabular}

\section{QUIPURAMAYOC}


Documentos Jurídicos / Disposiciones Legislativas LEY PENAL CONTRA EL LAVADO DE ACTIVOS LEY N. ${ }^{\circ} 27765$

Artículo $1^{\circ}$.- Actos de Conversión y Transferencia El que convierte o transfiere dinero, bienes, efectos 0 ganancias, cuyo origen ilícito conoce o puede presumir, con la finalidad de evitar la identificación de su origen, su incautación o decomiso, será reprimido con pena privativa de la libertad no menor de ocho ni mayor de quince años y con ciento veinte a trescientos cincuenta días multa.

Artículo $\mathbf{2}^{\circ}$.- Actos de Ocultamiento y Tenencia El que adquiere, utiliza, guarda, custodia, recibe, oculta o mantiene en su poder dinero, bienes, efectos o ganancias, cuyo origen ilícito conoce o puede presumir, con la finalidad de evitar la identificación de su origen, su incautación o decomiso, será reprimido con pena privativa de la libertad no menor de ocho ni mayor de quince años y con ciento veinte a trescientos cincuenta días multa.

\section{Artículo $3^{\circ}$.- Formas Agravadas}

La pena será privativa de la libertad no menor de diez ni mayor de veinte años y trescientos sesenta y cinco a setecientos treinta días multa, cuando:

a) El agente utilice o se sirva de su condición de funcionario público o de agente del sector inmobiliario, financiero, bancario o bursátil.

b) El agente comete el delito en calidad de integrante de una organización criminal.

La pena será privativa de la libertad no menor de veinticinco años cuando los actos de conversión o transferencia se relacionen con dinero, bienes, efectos o ganancias provenientes del tráfico ilícito de drogas, el terrorismo 0 narcoterrorismo.

Artículo $4^{\circ}$.- Omisión de Comunicación de Operaciones o Transacciones Sospechosas

El que incumpliendo sus obligaciones funcionales o profesionales, omite comunicar a la autoridad competente, las transacciones u operaciones sospechosas que hubiere detectado, según las leyes y normas reglamentarias, será reprimido con pena privativa de la libertad no menor de tres ni mayor de seis años, con ciento veinte a doscientos cincuenta días multa, e inhabilitación no ma- yor de seis años, de conformidad con los incisos 1,2 y 4 del artículo $36^{\circ}$ del Código Penal.

Artículo $5^{\circ}$.- Reglas de Investigación

Para la investigación de los delitos previstos en esta ley, se podrá levantar el secreto bancario, la reserva tributaria y la reserva bursátil, por disposición de la autoridad judicial o a solicitud del Fiscal de la Nación. La información obtenida en estos casos sólo será utilizada en relación con la investigación de los hechos que la motivaron.

Artículo $6^{\circ}$.- Disposición Común

El origen ilícito que conoce o puede presumir el agente del delito podrá inferirse de los indicios concurrentes en cada caso.

El conocimiento del origen ilícito que debe conocer o presumir el agente de los delitos que contempla la presente ley, corresponde a conductas punibles en la legislación penal como el tráfico ilícito de drogas; delitos contra la administración pública; secuestro; proxenetismo; tráfico de menores; defraudación tributaria; delitos aduaneros u otros similares que generen ganancias ilegales, con excepción de los actos contemplados en el artículo $194^{\circ}$ del Código Penal.

En los delitos materia de la presente ley, no es necesario que las actividades ilícitas que produjeron el dinero, los bienes, efectos o ganancias, se encuentren sometidas a investigación, proceso judicial o hayan sido objeto de sentencia condenatoria.

Artículo $7^{\circ}$.- Prohibición de Beneficios Penitenciarios Los sentenciados por el delito previsto en último párrafo del artículo $3^{\circ}$ de la presente Ley no podrán acogerse a los beneficios penitenciarios de redención de la pena por el trabajo y la educación, semi-libertad y liberación condicional.

Artículo $8^{\circ}$.- Norma Derogatoria

Deróganse los artículos $296^{\circ}$-A y $296^{\circ}$-B del Código Penal.

Comuníquese al señor Presidente de la República para su promulgación.

\section{CARLOS FERRERO}

Presidente del Congreso de la República

HENRY PEASE GARCÍA

Primer Vicepresidente del Congreso de la República 


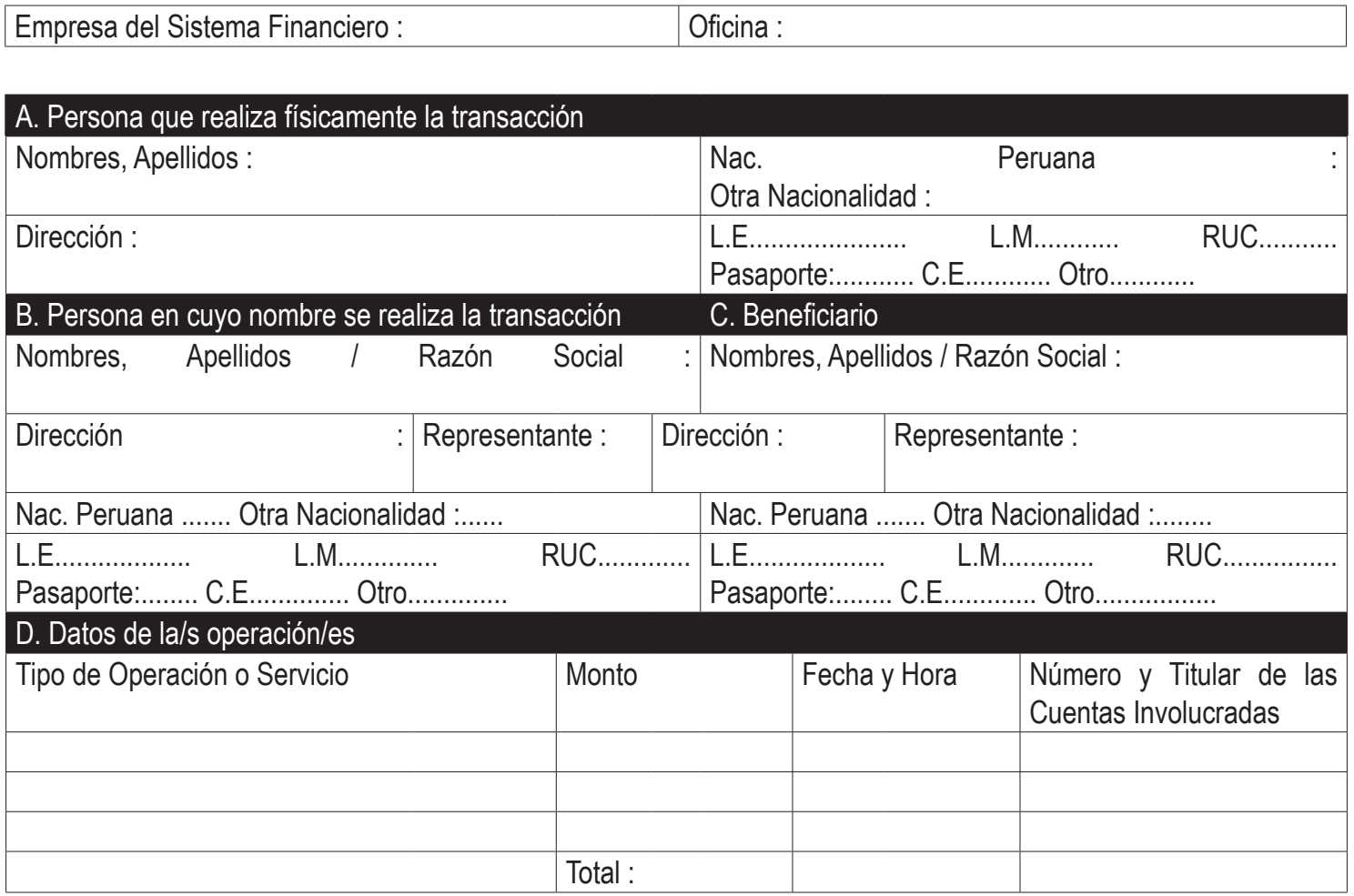

\section{Firma de la persona que realiza \\ la transacción \\ (o huella digital)}

\section{CONTENIDO BÁSICO DEL MANUAL DE PREVENCIÓN DEL LAVADO DE DINERO}

El manual de prevención del lavado de dinero que las empresas elaboren debe contener, por lo menos, la siguiente información:

\section{Políticas}

Los lineamientos generales establecidos en el Código de Conducta de la Empresa con el objetivo de prevenir el lavado de dinero en la institución, los mismos que deben ser suscritos por sus empleados, funcionarios, accionistas, directores y cualquier representante autorizado.

\section{Mecanismos de prevención}

2.1. Mecanismos de prevención del lavado de dinero basados en los criterios de conocimiento del cliente y del mercado establecidos en la presente Norma.

2.2. Medios de verificación de la información respecto a clientes de acuerdo a lo seńalado en el numeral 2 del artículo $375^{\circ}$ de la Ley General.

2.3. Medidas para obtener información acerca de la verdadera identidad de las personas, de acuerdo a lo señalado en el numeral 3 del artículo $375^{\circ}$ de la Ley General. 
2.4. Programas de capacitación interna conforme a lo establecido en el literal b) del numeral 1 del artículo $380^{\circ}$ de la Ley General y el numeral 2.2 de esta Resolución.

2.5. Controles internos implementados por la Empresa para prevenir o detectar el lavado de dinero según lo establecido en el numeral 1 del artículo 380 de la Ley General.

2.6. Elementos que determinan el buen criterio de la Empresa señalado en el numeral 3.1 del presente Reglamento.

2.7. Clientes exceptuados del registro de transacciones en efectivo en base al buen criterio de la empresa y su justificación.

2.8. Sistema para evaluar los antecedentes personales, laborales y patrimoniales del personal de conformidad con lo señalado en el literal a) del numeral 1 del artículo $380^{\circ}$ de la Ley General

2.9. Señales de alerta para la detección de transacciones inusuales

2.10. Sanciones internas por incumplimiento del Código de Conducta o de las disposiciones establecidas en la Ley General o en esta Norma.

\section{Procedimientos de registro y reporte}

3.1. Procedimientos de registro y conservación de la información y documentación requerida por el artículo $375^{\circ}$ de la Ley General; así como respecto de transacciones en efectivo por encima de los montos determinados por esta Norma.

3.2. Formularios requeridos según el artículo $377^{\circ}$ de la Ley General y el numeral 3 de esta Norma.
3.3. Procedimiento de comunicación al Fiscal de la Nación de transacciones sospechosas.

3.4. Procedimientos internos de consulta y reporte de transacciones inusuales y sospechosas.

\section{Revisión del sistema de prevención}

4.1. Identidad y cargo del oficial de cumplimiento; así como sus funciones y responsabilidades.

4.2. Informe anual del Oficial de Cumplimiento.

4.3. Informes de auditoría interna, de auditoría externa y de las empresas clasificadoras de riesgo, conforme a lo señalado en el numeral 5 de esta Resolución.

\section{CONCLUSIONES}

- La difusión de las normas pertinentes contra el Lavado de Dinero en los países latinoamericanos resulta fundamental para lograr una mayor eficacia de las mismas en el combate contra la empresa criminal, más allá de la represión del delito en sí mismo considerado y de la simple represión penal al delincuente.

- La acción de las autoridades contra el lavado de activos tiene la mayor importancia en el entorno actual, en el cual se han modificado de manera sustancial las políticas contra la delincuencia.

- El sector financiero recibe y canaliza buena parte del flujo de capitales de la economía, lo cual facilita que el dinero de procedencia ilícita se confunda con recursos de origen legal.

- El sector financiero es especialmente vulnerable a ser utilizado sin su consentimiento ni conocimiento para el lavado de activos. 